\title{
Case Report: Papillary Thyroid Cancer in a Patient with Celiac Disease and Thalassemia Trait
}

\author{
Afaf Albattah $^{a}$ Yahia Imam $^{b} \quad$ Ahmed Osman Saleh $^{c} \quad$ Khalid Ahmed $^{a}$ \\ Tarek Aboursheid $^{d}$ Samah Kohla $^{\mathrm{e}}$ Shehab Mohamed ${ }^{\mathrm{a}}$ \\ aDepartment of Hematology, National Center for Cancer Care and Research (NCCCR), \\ Hamad Medical Corporation, Doha, Qatar; ${ }^{b}$ Department of Neurology, Weill Cornell \\ Medical College, Doha, Qatar; 'Department of Endocrinology, Hamad Medical Corporation, \\ Doha, Qatar; ${ }^{\mathrm{d} D e p a r t m e n t}$ of Internal Medicine, Hamad Medical Corporation, Doha, Qatar; \\ eLaboratory Department, National Center for Cancer Care and Research, Hamad Medical \\ Corporation, Doha, Qatar
}

Keywords

Celiac disease $\cdot$ Thalassemia $\cdot$ Papillary thyroid cancer

\section{Abstract}

Thyroid cancer is the most frequent endocrine neoplasm in the general population. Common risk factors include gender, radiation exposure, and genetic backgrounds. The association of papillary thyroid cancer and celiac disease has frequently been reported in the literature; however, the association of papillary thyroid cancer and thalassemia trait is rare. Likewise, the association of thalassemia major and celiac disease is also rare. We hereby report a unique case of papillary thyroid cancer in a patient with celiac disease and thalassemia trait.

\section{Introduction}

Thyroid cancer is the most prevalent endocrine neoplasm in the general population with an incidence of 5-10/100,000 per year [1]. In females, thyroid cancers are the fifth most common cancer, with papillary thyroid cancer making about $80 \%$ of all types $[2,3]$. The annual mortality rate among women is nearly double the rate of men [1]. The increased risk of papillary thyroid cancer in patients with celiac disease is reported well in the literature, but the association of papillary thyroid cancer with thalassemia trait is not very common. Moreover, thalassemia and celiac disease association is rare. Here we report a unique case of celiac disease, thalassemia trait, and papillary thyroid cancer at a young age. 


\section{Case Reports in Oncology}

\begin{tabular}{l|l}
\hline Case Rep Oncol 2020;13:1364-1367 \\
\hline DOI: 10.1159/000511068 & $\begin{array}{l}\text { @ 2020 The Author(s). Published by S. Karger AG, Basel } \\
\text { www.karger.com/cro }\end{array}$ \\
\hline
\end{tabular}

Albattah et al.: Papillary Thyroid Cancer in a Patient with Celiac Disease and Thalassemia Trait

\section{Case Presentation}

A 36-year-old lady, known to have alpha thalassemia trait evident by hemoglobin ( $\mathrm{Hb})$ electrophoresis, underwent splenectomy in 1996 with reactive thrombocytosis since then. She had multiple blood transfusions in the past. No imaging was done to determine iron overload; however, there was no biochemical evidence of iron overload. Her iron profile and ferritin were within normal to low range. She was diagnosed with celiac disease in January 2013, confirmed with biopsy and serological testing, non-compliant with gluten-free diet. In July 2013, she was found to have euthyroid multinodular goiter, followed in primary health center, but due to progressive enlargement and compressive symptoms she was referred for surgery. She underwent total thyroidectomy in March 2019, which revealed multifocal papillary thyroid carcinoma (stage mpT1b). Postoperative radioactive iodine was not recommended due to low-risk thyroid cancer; this was backed up with second opinion from a specialized center in the USA. Her course was complicated with postoperative hypoparathyroidism and refractory hypocalcemia. She is currently on suppressive dose of levothyroxine, calcium, and vitamin D with annual thyroid cancer surveillance with neck ultrasound and thyroglobulin level monitoring.

\section{Discussion}

Here we present a unique case of papillary thyroid cancer in a patient with celiac disease and thalassemia trait. She is currently followed in endocrine clinic for postoperative refractory hypocalcemia and thyroid cancer surveillance.

The etiology of papillary thyroid cancer may vary; it could be due to exposure to radiation, gender, or association with certain familial malignant syndromes such as familial adenomatous polyposis and Gardener syndromes [4]. Moreover, BRAF mutation, which is associated with rapid papillary thyroid cancer growth and higher mortality, was reported in other malignances; hairy cell leukemia and melanoma [5].

One of the associations gaining medical attention recently is malignancy as a complication of thalassemia disease. Thalassemia is an inherited autosomal recessive disorder of hemoglobin synthesis which leads to variable types of anemia. Thalassemia patients nowadays live longer due to advances of medical knowledge and healthcare. However, new complications begin to emerge such as hematologic and solid organ malignancies. Data from a large multicenter registry for patients with beta thalassemia showed that cancer was the fifth most frequent cause of death in this population with a prevalence of 3.6\% [6]. Thalassemia patients had 1.47-fold overall risk of developing cancer compared with the cohort after adjusting for age, sex, and comorbidities. In addition, patients who are transfusion dependent were at about 9-fold more at risk for developing hematologic and abdominal malignancies when compared to patients who are not transfusion dependent. Women with thalassemia were also found to have $70 \%$ higher cancer risk compared to the control [7].

The incidence of thyroid cancer, especially papillary carcinoma in thalassemia patients was found to be higher than in the general population. In 2011 the first two case reports of thyroid cancer among beta thalassemia patients were reported, followed by another three case reports from Italy [8, 9]. Both case series speculated iron overload as a causative mechanism for developing the cancer, as all patients suffered from iron overload. Another possibility was hepatitis $\mathrm{C}(\mathrm{HCV})$ infection as a potential carcinogenic infection. To date there are no reports in the literature linking alpha thalassemia trait to any cancer. Moreover, our patient has neither iron overload nor HCV infection that could explain the carcinogenic hypothesis that was reported earlier.

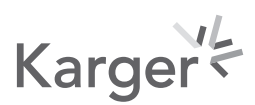


Celiac disease is an immune-mediated enteropathy of the small intestine caused by sensitivity to gluten. Symptoms may vary, but gastrointestinal symptoms are the most common, which include abdominal pain, distention, diarrhea, vomiting, and constipation. Other symptoms could include symptoms of malabsorption such as iron deficiency anemia and bone and minerals disease $[10,11]$. Celiac disease is not only confined to the gastrointestinal tract, but it is also linked to several malignancies. It is known to be linked to lymphomas, Bor T-cell lymphomas. Other cancers like squamous cell carcinoma of the esophagus and oropharynx and small intestinal adenocarcinoma were also reported [12-14]. In recent years, several reports about the association of celiac disease with papillary thyroid cancer have emerged. A study from Italy reported 2.5-fold increased risk of papillary thyroid cancer for celiac disease patients [15]. Our patient was diagnosed with thalassemia, which is an additional risk factor to develop cancer. She was not compliant with gluten-free diet, but this was not found to correlate with increased risk for papillary cancer [15]. On the other hand, a large population-based Swedish cohort study concluded that there is no increased risk of any thyroid cancer in patients with celiac disease, but all thyroid cancers in celiac disease occurred in female patients [16].

Multinodular thyroid was reported as a risk factor for thyroid cancer in a multicenter study that reported higher than expected incidental thyroid cancer rate of 17.5 and $18.3 \%$ for nodular goiter and toxic multinodular goiter, respectively [17]. On the other hand, a retrospective cohort study concluded that multinodularity does not increase the risk of thyroid malignancy [18]. However, as these studies were done on patients who underwent surgery, it cannot be applied to all patients with multinodular goiter. Our patient had all three potential risk factors for developing thyroid cancer.

\section{Conclusion}

In conclusion, the occurrence of thyroid cancer in adult thalassemic patients is an emerging concern for physicians. Adding another two potential risk factors increases the risk for thyroid malignancies. Patients with thalassemia with or without other potential risk factors for thyroid cancer should be followed in a thyroid specialist clinic. This requires the need for an annual thyroid ultrasound surveillance and biopsy of suspicious nodules.

\section{Statement of Ethics}

Our research complies with the guidelines for human studies and was conducted ethically in accordance with the World Medical Association Declaration of Helsinki. Our local ethics committee in Hamad Medical Corporation (Medical Research Center) has granted permission for this case report to be published on condition that no patient-identifiable data (including patient name and photograph) are included. The approval was obtained under the following number: MRC 04-20-691. The same manuscript was submitted to the Medical Research Center and was reviewed prior to giving the permission for publication. Informed written consent for publication was not asked for by the Medical Research Center since no data that can potentially and clearly identify the patient found in the case description.

\section{Karger'k}




\section{Conflict of Interest Statement}

The authors declare that they have no conflict of interest with regard to the writing and publication of this article.

\section{Funding Sources}

The authors did not receive funding for this publication.

\section{Author Contributions}

All authors listed on the title page contributed equally.

\section{References}

1 Govoni MR, Sprocati M, Fabbri E, Zanforlin N, De Sanctis V. Papillary Thyroid Cancer in Thalassaemia. Pediatr Endocrinol Rev. 2011 Mar;8(Suppl 2):314-21.

2 https: //www.cancer.org/content/dam/cancer-org/research/cancer-facts-and-statistics/annual-cancerfacts-and-figures/2020/cancer-facts-and-figures-2020.pdf.

3 Thyroid Cancer. American Cancer Society. http://www.cancer.org/acs/groups/cid/documents/ webcontent/003144-pdf.pdf. Updated January 20, 2012. Accessed March 8, 2012.

4 Musholt TJ, Musholt PB, Petrich T, Oetting G, Knapp WH, Klempnauer J. Familial papillary thyroid carcinoma: genetics, criteria for diagnosis, clinical features, and surgical treatment. World J Surg. 2000;24(11):1409-17.

5 Mohamed SF, Helmi F, El-Akiki S, El Omri H, Nashwan A, Yassin MA. Concomitant BRAF Mutation in Hairy Cell Leukemia and Papillary Thyroid Cancer: Case Report. Case Rep Oncol. 2019;12(3):922-7.

6 Borgna-Pignatti C, Rugolotto S, De Stefano P, Zhao H, Cappellini MD, Del Vecchio GC, et al. Survival and complications in patients with thalassemia major treated with transfusion and deferoxamine. Haematologica. 2004; 89(10):1187-93.

7 Chung WS, Lin CL, Lin CL, Kao CH. Thalassaemia and risk of cancer: a population-based cohort study. J Epidemiol Community Health. 2015;69(11):1066-70.

8 Poggi M, Sorrentino F, Pascucci C, et al. Malignancies in $\beta$-thalassemia patients: first description of two cases of thyroid cancer and review of the literature. Hemoglobin. 2011;35(4):439-46.

9 De Sanctis V, Campisi S, Fiscina B, Soliman A. Papillary thyroid microcarcinoma in thalassaemia: an emerging concern for physicians? Georgian Med News. 2012;210(210):71-6.

10 Rubio-Tapia A, Hill ID, Kelly CP, Calderwood AH, Murray JA, American College of Gastroenterology. ACG clinical guidelines: diagnosis and management of celiac disease. Am J Gastroenterol. 2013;108(5):656-77.

11 Kneepkens CM, von Blomberg BM. Clinical practice: coeliac disease. Eur J Pediatr. 2012;171(7):1011-21.

12 Holmes GK, Prior P, Lane MR, Pope D, Allan RN. Malignancy in coeliac disease - effect of a gluten free diet. Gut. 1989;30(3):333-8.

13 Green PH, Fleischauer AT, Bhagat G, Goyal R, Jabri B, Neugut AI. Risk of malignancy in patients with celiac disease. Am J Med. 2003;115(3):191-5.

14 Askling J, Linet M, Gridley G, Halstensen TS, Ekström K, Ekbom A. Cancer incidence in a population-based cohort of individuals hospitalized with celiac disease or dermatitis herpetiformis. Gastroenterology. 2002; 123(5):1428-35.

15 Volta U, Vincentini O, Silano M, Collaborating Centers of the Italian Registry of Celiac Disease. Papillary cancer of thyroid in celiac disease. J Clin Gastroenterol. 2011;45(5):e44-6.

16 Ludvigsson JF, Lebwohl B, Kämpe O, Murray JA, Green PH, Ekbom A. Risk of thyroid cancer in a nationwide cohort of patients with biopsy-verified celiac disease. Thyroid. 2013;23(8):971-6.

17 Smith JJ, Chen X, Schneider DF, Broome JT, Sippel RS, Chen H, et al. Cancer after thyroidectomy: a multi-institutional experience with 1,523 patients. J Am Coll Surg. 2013;216(4):571-9.

18 Lin YS, Wu HY, Yu MC, Hsu CC, Chao TC. Patient outcomes following surgical management of multinodular goiter: Does multinodularity increase the risk of thyroid malignancy? Medicine (Baltimore). 2016;95(28): e4194. 